\title{
Referenciação e Polidez na (Re)Construção do Self e do Outro: resgatando a história de amor de Jayme e Maria ${ }^{1}$
}

Referenciation and Politeness in the (Re)Construction of Self and OF OTHER: RECOVERING THE LOVE STORY OF JAYME AND MARIA

Andrezza Alves QUEIROZ* Maria Helenice Araújo COSTA**

Resumo: Este artigo tem o propósito de reconstituir a história de Jayme e Maria, casal de namorados dos anos 30, a partir da (re)construção do self e do outro, na correspondência amorosa desse casal, a qual constitui o corpus "Acervo Jaime-Maria", disponibilizado na página virtual Laboratório de História do Português Brasileiro (Labor-histórico PB). Para atingir esse objetivo, apoiamo-nos em textos dos campos teóricos da referenciação e da polidez, além de textos teóricos acerca do contexto. Em nossa análise, discutimos o levantamento quantitativo de todas as formas de tratamento usadas na

\footnotetext{
* Doutoranda do Programa de Pós-Graduação em Linguística Aplicada da Universidade Estadual do Ceará. Mestra em Linguística Aplicada pela Universidade Estadual do Ceará (2015). Bolsista da Coordenação de Aperfeiçoamento de Pessoal de Nível Superior (CAPES).Contato: andrezzaaqueiroz@gmail.com.

** Doutora em Linguística pela Universidade Federal do Ceará (2007). Professora do curso de Letras e do Programa de Pós-Graduação em Linguística Aplicada da Universidade Estadual do Ceará. Membro do Grupo Protexto da Universidade Federal do Ceará. Contato: mariahelenicearaujo@gmail.com.
}

${ }^{1}$ Este artigo constitui um recorte do trabalho dissertativo intitulado Referenciação e Polidez em cartas de amor: o resgate da história de Jayme e Maria por meio da (re)construção do self e do outro, disponível no site do Programa de Pós-Graduação em Linguística Aplicada (PosLA) da Universidade Estadual do Ceará. 
correspondência ( 92 cartas no total) trocada entre Jayme e Maria e analisamos alguns trechos das cartas que nos permitem reunir elementos suficientes para reconstituir a história desse casal. Alguns dos resultados a que chegamos demonstraram que as inferências ampliaram a superfície textual do discurso, o que contribuiu para a reconstituição da história dos protagonistas e que a polidez linguística enriqueceu a interpretação dos dados, uma vez que deixou os discursos dos interlocutores mais acessíveis.

Palavras-chave: Referenciação. Polidez. Cartas pessoais.

Abstract: This article purpose is of reconstitude the story of Jayme e Maria, loving couple from the Thirties, through the (re)construction of self and of other, in their love correspondence, which represent the corpus "Acervo Jaime-Maria", offered in the virtual page Laboratório de História do Português Brasileiro (Labor-histórico PB). In order to fulfill this purpose, we used as support the texts from the referenciation and politeness theoretical fields, as well as theoretical texts about context. In our analysis, we discussed the quantitative survey of all expressions of treatment used in correspondence (a total of ninety two) exchanged by Jayme and Maria and we analyzed some excerpts from these letters which allow us join enough data to reconstitute the story of this couple. The results we found prove that the inferences amplifyed the text of discourse, which endorsed the recovery of the characters' story and, on the other hand, the linguistic politeness contributed to the interpretation of the data, which made the speakers' utterances more accessible.

Keywords: Referenciation. Politeness. Personal letters.

\section{Considerações Iniciais}

A ideia de uma relação especular entre linguagem e mundo há muito foi abolida pelos estudiosos dos fenômenos linguísticos sob os mais variados prismas. Para além do senso comum, não há mais a crença na existência de um fio ligando palavras e significados, situação que implicaria a possibilidade de se preservarem os conceitos tal qual tivessem estes sido formulados e verbalizados. 
Negar essa relação representacionista leva, porém, à necessidade de se explicar o tipo de relação que inegavelmente existe. O célebre aforismo wittgensteiniano, que atribui o significado das palavras ao uso, leva-nos a entender que esse uso ocorre dentro dos "jogos de linguagem", das "formas de vida" que guardam entre si "semelhanças, parentescos" (WITTGENSTEIN, 1996, p. 51, \$ 66). Como bem observa Marcuschi (2007, p. 41), essa relação é "configurada por ações conjugadas, social e cognitivamente".

É assim que, segundo entendemos, os discursos vão guardando as marcas das práticas desenvolvidas, dos jogos em que atuaram os agentes sociais, nos quais viveram os papéis que lhes foram dados ao longo de suas vidas. É pensando assim que objetivamos, neste artigo, dar a conhecer a história de Jayme e Maria, um casal de namorados que viveu seu romance na década de 30 do século XX.

Vale ressaltar que a discussão que desenvolvemos aqui é parte de uma pesquisa maior, durante a qual analisamos um corpus composto por 92 cartas trocadas entre o casal. Neste trabalho, analisamos 9 exemplares que julgamos relevantes para apoiar nossa discussão.

Para a análise, tomamos por base os pressupostos teóricos da Referenciação e da Teoria da Polidez. Entendemos que as recategorizações verificadas no interior de cada carta, assim como ao longo da história do relacionamento, registrada pela troca de mensagens, nos dariam a conhecer os personagens que foram objeto de nosso estudo. Já o olhar sob a ótica da Polidez complementaria essa compreensão, sugerindo-nos inclusive o modo como teria evoluído a relação.

Organizamos este artigo da seguinte forma: nas três seções iniciais, realizamos uma breve discussão teórica acerca das noções de referenciação e intersubjetividade, polidez e contexto. Nas seções seguintes, descrevemos a procedência do nosso corpus, apresentamos as formas referenciais vocativas das cartas de Jayme e Maria, para, depois, reconstituirmos sucintamente a história de nossos protagonistas. Para encerrar o texto, tecemos nossas considerações finais. 


\section{A Referenciação e a Intersubjetidade: uma breve discussão teórica}

Apesar de a questão da referência ainda promover muitas discussões nos mais variados quadros conceituais, ainda ocupa lugar de destaque nos estudos da linguagem a tese não representacionista, segundo a qual a relação entre linguagem e mundo não é previamente estabelecida de forma biunívoca, "mas configurada por ações conjugadas, social e cognitivamente" (MARCUSCHI, 2007, p. 41). Ao adotarmos tal posicionamento, estamos optando por seguir o caminho alternativo proposto por Mondada e Dubois (2003), em que as entidades discursivas são elaboradas nas negociações intersubjetivas e modificam-se segundo os contextos, o que não permite conhecer o mundo e as coisas de forma pronta e acabada. Em outras palavras, para as autoras, mesmo que um referente se encontre estabilizado, ele "pode ser 'decategorizado', tornado instável, evoluir sob o efeito de uma mudança de contexto ou de ponto de vista" (p. 27), uma vez que as entidades discursivas apresentam uma imanente instabilidade.

Foi essa perspectiva instável de ver o mundo e as coisas que nos motivou a voltar o olhar para o discurso de Jayme e Maria. Embora supondo que esses discursos pareçam estabilizados pelo tempo em que foram escritos, entendemos que nossa percepção de pesquisadores, sobre as marcas impressas nas cartas pelos personagens e acerca do contexto sócio-histórico em que eles estavam inseridos, permitiu-nos inferir sentidos construídos durante a interação do casal.

A correspondência de Jayme e Maria nos fez ver com mais clareza que a referenciação seria construída sociocognitiva e colaborativamente entre os sujeitos em interação e não representaria somente um reflexo especular das entidades discursivas. Observamos, então, que a construção de objetos cognitivos e discursivos é proveniente da negociação entre os sujeitos. Sendo assim, como, em nossa análise, estamos voltados para as formas que Jayme e Maria utilizaram para tratar o self e o outro, precisamos, mesmo que de forma breve, situar as concepções de categorização, de recategorização e de intersubjetividade.

Para Mondada e Dubois (2003), as categorias não estão prontas e acabadas no mundo, mas são "o resultado de reificações práticas e históricas de processos complexos, compreendendo discussões, controvérsias, 
desacordos" (p. 28). Assim, podemos entender que a categorização constitui um processo instável, visto que pode transformar-se sincrônica e diacronicamente. Em síntese, segundo Ciulla (2008, p. 31, grifo da autora),

todo ato de referir implica, também, categorizar, pois ao escolher uma expressão, entre todas as opções que julgar adequadas, incluindo-se aí as invenções, adaptações e transformações, o falante privilegia alguns aspectos e algumas semelhanças de família em detrimento de outros, de acordo com as discriminações (ou abstrações ou generalizações, etc.) que a palavra escolhida pode comportar naquela situação de uso.

A autora destaca que essa seleção não se limita a um número definido de opções, uma vez que o falante, tendo em vista seus propósitos, pode criar expressões ou inventar categorias. Para Ciulla (2008), na verdade, a escolha de uma determinada expressão é "limitada apenas pela habilidade, memória e conhecimento do próprio falante e de seu interlocutor" (p. 32). A instabilidade das categorias no discurso, então, consoante Mondada e Dubois (2003), estaria mais ligada à pragmática dos enunciados do que à semântica dos objetos, até porque, conforme argumenta Marcuschi (2007, p. 89), "a realidade mundana não está segmentada da forma como a concebemos", mas, tendo em vista que o processo de categorização tem uma dimensão discursiva, o mundo comunicado é sempre reflexo do nosso agir comunicativo.

As categorias, portanto, "são elaboradas no processo dinâmico de interlocução cooperativamente desenvolvida” (MARCUSCHI, 2007, p. 93), o que nos lembra que, ao interagirmos, estamos produzindo colaborativamente nossas enunciações, as quais, nesse processo de construção, podem ser alimentadas e enriquecidas por interlocutores distintos. Esses possíveis acréscimos, nas palavras de Silva e Custódio Filho (2013), é que contribuem para a progressão textual. Para Cavalcante (2013), a recategorização estaria relacionada com a facilidade que determinadas entidades discursivas têm para transformar-se no decorrer da materialidade textual. Tais mudanças seriam, de acordo com a autora, reflexo das intenções, emotivas, expressivas, poéticas, por exemplo, do produtor do texto. $\mathrm{Na}$ 
correspondência de Jayme e Maria, os elementos linguísticos selecionados por esse casal nos deixaram, de certa forma, perceber a ligação afetiva que os unia e o cuidado que um tinha para com o outro. Observamos, então, que o casal de namorados se esforçava para recategorizar a si e ao outro com o intuito de exaltar o sentimento que os motivava.

Acreditamos, portanto, que Jayme e Maria empreendem a construção e reconstrução colaborativa das entidades discursivas. Dessa forma, não nos interessa observar somente as (re)construções intratextuais do self e do outro, mas também a progressão intertextual de tais construções no decorrer da troca comunicativa. É patente, assim, que, ao assumirmos uma perspectiva sociocognitivista, estamos valorando a interação e a negociação pública nas práticas discursivas, uma vez que a significação emerge das relações multissemióticas envolvidas nos contextos de uso.

Antes de imergir nas negociações discursivas, precisamos esclarecer que o sujeito ao qual estamos nos referindo assemelha-se ao proposto pelo Círculo Bakhtiniano, ou seja, um sujeito que é um agente "responsável por seus atos e responsivo ao outro", não um "fantoche" construído socialmente (SOBRAL, 2013, p. 24). Essa percepção de sujeito nos permite pôr em evidência o que vimos articulando até aqui, que as entidades discursivas são (re)construídas colaborativamente ao longo da interação.

Avesso ao posicionamento que considera a abstração da língua e à concepção que acredita no sujeito solipsista, Bakhtin concebe o sujeito como "um eu-para-si, condição de formação da identidade subjetiva, é também um eu-para-o-outro” (SOBRAL, 2013, p. 22). Assumindo, dessa maneira, uma percepção não monológica do mundo, Bakhtin afirma que a subjetividade seria concebida "no denso caldo do simpósio universal, sendo a alteridade e a intersubjetividade, portanto, absolutamente indispensáveis" (FARACO, 2009, p. 76). Assim, para o Círculo Bakhtiniano, o contexto social e histórico é sempre considerado, tanto no que diz respeito a atos não discursivos como também "em sua transfiguração discursiva, sua construção em texto/discurso" (p. 23).

Conforme menciona Santos (2013), a ampla visão acerca da essência do sentido, de sujeito e de linguagem articulada por Bakhtin está associada à percepção de sujeito sociocognitivo assumida por Marcuschi e defendida por nós neste trabalho. Salomão (1999, p. 71), adepta da concepção sociocognitivista e influenciada pelas ideias de Goffman (2011), argumenta 
que a interpretação funciona como uma representação dramática e a experiência social não desconsidera a semantização primária, "que corresponde ao investimento do sujeito em específico papel comunicativo, configurado frente à sua audiência, num trabalho de mútua determinação, através do qual se constrói a face."

A face ${ }^{2}$, de acordo com Goffman (2011, p. 15), não estaria encerrada dentro ou sobre o nosso corpo, mas seria "algo localizado difusamente no fluxo de eventos no encontro, que se torna manifesto apenas quando esses eventos são lidos e interpretados para alcançarmos as avaliações expressas neles". O termo face, utilizado por Goffman, pode ser percebido como o termo self, proposto por Mead (1973), para quem o self seria construído socialmente. Para Mead, o eu e o mim refletem a experiência social dos sujeitos, o que, de certa forma, nos remete às ideias de Goffman e nos conduz para a concepção de sujeito cunhada por Bakhtin, na qual o sujeito seria construído durante a interação com o outro. Dessa maneira, os termos self e outro que estamos utilizando neste trabalho estão de acordo com os posicionamentos de Bakhtin e de Goffman, uma vez que admitimos a construção social de nossos sujeitos ao longo do encadeamento intra e intertextual das cartas.

\section{As Perspectivas Teóricas da Polidez Linguística}

Para Goffman (2011), já há um vínculo social previamente estabelecido entre um determinado sujeito e seus possíveis interlocutores durante o processo interativo. Com o propósito de preservar a harmonia das relações interacionais, consoante o autor, as escolhas linguísticas seriam empreendidas cooperativa e equilibradamente, tendo em vista o interesse das partes envolvidas na interlocução. Para minimizar qualquer possível rompimento desse equilíbrio, o falante ${ }^{3}$ poderia empenhar-se em anular atos ameaçadores de face, por meio de estratégias discursivas que beneficiem a interação.

${ }^{2}$ Em Goffman (2011), o termo fachada é utilizado como sinônimo de face. No entanto, neste trabalho, utilizamos o termo face, do original em inglês.

${ }^{3}$ Os termos falante e ouvinte, utilizados neste trabalho, abrangem o interlocutor atuante em modalidade discursiva. 
Os indivíduos, de acordo com Goffman (2011) estão, com frequência, envolvidos em encontros sociais e assumem uma determinada maneira de agir para manifestar suas percepções da situação. Então, na busca de consolidar essa maneira de agir, eles sustentam uma determinada face. A face, segundo o autor, compreenderia as construções sociais que criamos, mantemos ou perdemos, em conformidade com nossos propósitos em relação a ela. A interação ${ }^{4}$ social, portanto, para Goffman, se assemelharia a um ritual, o qual não necessita do contato face a face para ocorrer e, diversas vezes, exibiria pistas de natureza ritualística das relações sociais.

O trabalho de face elaborado por Goffman (2011) motivou, além de estudos que tratam da construção da identidade em interações face a face, trabalhos que cuidam da polidez linguística, como, por exemplo, a teoria desenvolvida por Brown e Levinson (1987), na qual a concepção de face apresentada por Goffman ancorou a elaboração de diversificadas estratégias de polidez. Além desse estudo, diversas pesquisas, como a de Leech (1983, 2005), alicerçaram outros trabalhos que lidam com a polidez linguística. A teoria de Leech apresenta dois momentos: um primeiro, que recebeu muitas críticas, e um segundo, que demonstra mais afinidade com a perspectiva que adotamos, o qual trata a polidez como um fenômeno que pode variar nas diferentes culturas.

Nesse segundo momento, Leech (2005), afastando-se do Princípio de Polidez, lançado em 1983, postula a Grande Estratégia de Polidez (GEP), que abrange as seguintes regras pragmáticas: generosidade; tato; aprovação; modéstia; obrigação (do falante para o ouvinte); sentimento-reticente; concordância; obrigação (do ouvinte para ofalante); opinião-reticente; e simpatia. No entanto, nem todas essas regras articuladas por Leech foram úteis para nossa discussão. Enfatizamos, portanto, as regras aprovação, que compreende os elogios e os cumprimentos,

${ }^{4}$ Segundo Goffman (1975), interagir significa influenciar de forma recíproca, em presença física, os indivíduos acerca das ações uns dos outros. Mesmo que o autor saliente a presença física para a ocorrência da interação, para nós, as suas considerações também funcionam para documentos escritos, como, por exemplo, nossa amostra neste trabalho, visto que, quando adotamos um posicionamento sociocognitivista, consideramos que os elementos linguísticos, associados a distintas semioses, instruem o interlocutor para a montagem da "cena social" (p. 23). 
e modéstia, que trata da avaliação pessoal, como a autodepreciação, por exemplo, como as mais adequadas para apoiar nossa análise.

\section{A Emergência e a Incorporação: o que as pistas nos dizem}

Um dos aspectos centrais, para Hanks (2008), nos estudos das últimas décadas sobre linguagem tem sido a preocupação com a relação entre linguagem e contexto. Em decorrência da ampla dimensão desses estudos, diversos posicionamentos acerca da noção de contexto emergiram. Entre essas diversas abordagens, o autor destaca, além das abordagens individualistas, em que a produção do enunciado constitui o ponto central para gerar o contexto, as abordagens denominadas globais, nas quais o contexto não se encontra localmente centrado, mas se prolonga por extensões contextuais mais amplas.

Baseando-se nos pressupostos da antropologia linguística e evitando adotar uma perspectiva local ou global de contexto, Hanks (2008) integra os distintos níveis de análise. Em sua nova abordagem de contexto, o autor postula duas dimensões contextuais: a emergência e a incorporação. A emergência, por um lado, envolveria aspectos da atividade enunciativa que se manifestam da produção e da recepção dos enunciados. A incorporação, por outro lado, trataria da situação dos enunciados vista em contextos mais amplos. Pleiteando a mesclagem entre essas duas dimensões na constituição do contexto, Hanks (2008) acredita, então, na existência de um vínculo dinâmico entre a incorporação contextual e a construção dos sujeitos "que se engajam nos contextos" (p. 195). Essa crença do autor faz mais sentido quando nos voltamos para Jayme e Maria, uma vez que eles, de certa maneira, não eram somente sujeitos individuais, mas eram formados culturalmente pela sociedade patriarcal que os envolvia.

Estamos atribuindo parte da responsabilidade pela formação dos personagens-alvo de nossa análise levando em conta o que observa Del Priore (2006). Segundo essa autora, na passagem do século XIX para o século XX, mesmo com as mudanças advindas da industrialização, da imigração e da urbanização, os casamentos ainda eram influenciados pela família e pelos amigos. As moças teriam de eleger um "bom partido", que "era o rapaz honesto e trabalhador, capaz de manter a família com conforto" (p. 308). 
Endossando essa mesma ideia, Sacramento (2006) confirma que o casamento conferiria a responsabilidade pela felicidade do lar à mulher. Segundo a autora, a mulher "deveria estar à disposição de seu marido e da família a qualquer momento. Deveria ser prendada, recatada, mas, ao mesmo tempo, esmerada em sua aparência, para que o homem não se sentisse atraído pelas mulheres da rua" (p. 322). Del Priore (2006, p. 311) fortalece a colocação de Sacramento ao citar o seguinte trecho do Jornal das Moças, publicado em outubro de 1955: “a arte de ser mulher exige muita perspicácia, muita bondade. Um permanente sentido de prontidão e alerta para satisfazer às necessidades dos entes queridos".

\section{As Cartas de Jayme e Maria: de onde vem o corpus?}

Nosso corpus é constituído por cartas de um casal de namorados, Jayme Oliveira Saraiva e Maria Ribeiro da Costa, escritas entre os anos de 1936-1937 e retiradas do site Laboratório de História do Português Brasileiro (Laborhistórico PB), da Universidade Federal do Rio de Janeiro. O acervo disponibilizado nesse site abrange o total de 97 cartas. Desse total, percebemos que cinco cartas se repetiam. Em razão disso, contabilizamos as cartas repetidas apenas uma vez, o que nos fez chegar ao total de 92 cartas.

Para entender melhor o fluxo da correspondência trocada entre o casal, organizamos os dados em um quadro no formato Word no qual a interação entre os namorados é representada. Dispomos duas células no quadro para cada participante, a primeira com a transcrição das cartas e a segunda com as formas de tratamento utilizadas pelos dois sujeitos, como mostra o Quadro 1, a seguir, que representa somente um turno da correspondência entre Jayme e Maria. 


\section{Quadro 1 - Cartas trocadas entre Jayme e Maria}

\begin{tabular}{|c|c|c|c|}
\hline \multicolumn{2}{|l|}{ Jayme } & & \\
\hline Carta 8 - 11 de setembro de 1936 (word) & $\begin{array}{c}\text { Formas de } \\
\text { tratamento } \\
\text { direcionadas a } \\
\text { Maria }\end{array}$ & Maria & \\
\hline \multirow{3}{*}{$\begin{array}{l}\text { Rio de Janeiro } 10 \text { de Setembro de } 1936 \\
\text { Minha Mariquinhas } \\
\text { Desejo-te muitas felicidades, assim como aos teus, peco- } \\
\text { te desculpas, da ultima carta não ter falado neles, como } \\
\text { tú sabes todo o meu sentido esta preso em voce, que } \\
\text { quando começo a escrever- te esqueço-me até do mundo. } \\
\text { Tenho umas } \\
\text { novidadesinhas que muito te agradarão, no ultimo dia } \\
\text { que subimos juntos, a noite, eu e minha mãe estivemos } \\
\text { conversando, então ela falou muito a teu respeito, } \\
\text { demonstrou estar muito interessada em voce, chegou a } \\
\text { chorar, disse que ela e papai foram os culpados por tudo } \\
\text { que houve, falou tambem que tem a certeza que nós não } \\
\text { acabamos, e que dentro em breve voce voltará a } \\
\text { frequentar a nossa casa. Minha mãe falou também, que } \\
\text { não se metia em mais nada, } \\
\text { Porque se fosse o nosso destino nos casavamos mesmo } \\
\text { e não adiantava estar se me-tendo, ela culpa somente a } \\
\text { sua irmã, a sua irmã é que foi afronta-la. Minha querida } \\
\text { essa conversa alegrou-me tanto que sinto vontade de } \\
\text { correr, pular cantar, mas começo a pensar que estás tão } \\
\text { longe, embora tú mores dentro do meu coração, eu só } \\
\text { posso ver-te somente nos sonhos. Eu não sei o que seria } \\
\text { de mim sem teu amo, tu és para mim a mesma coisa, que } \\
\text { é a agua para o viajante no deserto, o viajante no deserto } \\
\text { no deserto sem a agua morrerá, e eu sem teu amor } \\
\text { morrerei. só a ti e que eu devo o meus melhores } \\
\text { momentos, e as minhas noites de insonias. Aguardo a tua } \\
\text { carta com uma das maiores ansiedades, para desa-bafar } \\
\text { um pouquinho o meu coração sabendo noticias tuas, } \\
\text { Um abaraço para todo os teus. E para voce um } \\
\text { eternecido beijo em todas as vezes que pensa-res em } \\
\text { mim, porque eu sei que serão milhares de pei beijos por } \\
\text { dia. porque pensas tanto em mim. Jayme O. Saraiva } \\
\text { junto envio-te uns uns selos eu não os comprei porque } \\
\text { no escritório tem muitos, de modos que não faz falta. }\end{array}$} & \multirow[t]{3}{*}{$\begin{array}{c}\text { Minha } \\
\text { Mariquinhas } \\
\text { Minha querida }\end{array}$} & Carta 2 - 12 de setembro de 1936 (word) & $\begin{array}{c}\text { For mas de } \\
\text { tratamento } \\
\text { direcionadas a } \\
\text { Jayme }\end{array}$ \\
\hline & & $\begin{array}{l}\text { Paulo de Frontem, } 12-9-1936 \\
\text { Meu Queridinho Jayme } \\
\text { Desejo-te muitas felicidades assim como aos teus } \\
\text { eu e os } \\
\text { meus vamos muito bem grasas a Deus eu recebi a } \\
\text { tua carta do } 9 \text { e do } 10 \text { no dia } 11 \text { eu e a Ismenia } \\
\text { fomos buscar na estação por que o coreio nãotraes } \\
\text { em casa eu fiquei muito contente com as noticias } \\
\text { que mandaste diser sobre o meu respeito Jayme } \\
\text { manda-me dizer o que a tua mãe falou com voce } \\
\text { que eu estou anciosa para saber. Eu tenho sonhado } \\
\text { todas as noites com voce eu quando recebi as tuas } \\
\text { cartas fiquei tan contemte que chegei a chora eu } \\
\text { vin lendo pelo caminho e chora-ndo que a Ismenia } \\
\text { chegou me chamar de boba Jayme a qui cheve } \\
\text { muito e fais muito frio } \\
\text { [ } \uparrow \text { ] a Hilda manda um beijo para voce ela dise } \\
\text { que e um so me responde a carta sim [ } \uparrow \text { ] e muito } \\
\text { triste. Eu fiquei tam com temte saber que voce } \\
\text { vinha vem no dia } 20 \text { do corente voce manda-me } \\
\text { dizer a certesa sivem mesmo para eu ir esperarte } \\
\text { com Ismenia e manda dizer em que trem vem } \\
\text { abraços da minha irma dos meus sobrinha da } \\
\text { Ismenia e da Hilda. e desta que tanto te ama } \\
\text { muitos a braços e muitos beijo-e não se esqueca } \\
\text { de min } \\
\text { Maria Ribeiro da Costa } \\
\text { a minha irma manda-te pedir para voce trazer mais } \\
\text { um filme que depois ella paga a qui muito o } \\
\text { brigada pelos selos. Jayme não repares a minha } \\
\text { carta que não sei escrever }\end{array}$ & $\begin{array}{l}\text { Meu Queridinho } \\
\text { Jayme } \\
\text { Jayme }\end{array}$ \\
\hline & & {$[\downarrow]$ quando acabar de ler g rasga a carta $[\downarrow]$} & \\
\hline
\end{tabular}

Fonte: Queiroz (2015).

Das cartas trocadas entre o casal de namorados, organizadas no quadro completo com todas as 92 missivas, utilizamos alguns trechos, representados pelos recortes de 1 a 9, para a discussão dos dados articulada nas seções seguintes. 


\section{O Tratamento entre Jayme e Maria}

Antes de começarmos a contar a história de Jayme e Maria, empreendemos o levantamento quantitativo ${ }^{5}$ das expressões de tratamento articuladas por eles no corpus completo (92 cartas). Essa investigação foi necessária para tomarmos ciência acerca do tratamento negociado e construído entre esse casal. No primeiro contato com as cartas, o que despertou nosso interesse foi a variedade de expressões de tratamento (vocativos e assinaturas) que nossos protagonistas utilizaram para fazer referência um ao outro.

Nas cartas de Jayme, constatamos o uso de 202 diferentes modos de dirigir-se a Maria. Entre as expressões vocativas, algumas como minha carinha metade, que ocorre apenas uma vez, sugerem uma preocupação do autor com a variação do repertório, com a produção de um "texto novo". Inferimos que esses usos variados provinham de duas necessidades: a de sempre reforçar os sentimentos que tinha pela namorada por meio de um discurso lírico e, como recurso para atingir esse propósito, a “de [tentar] inovar o tratamento conferido à Maria ao construir novas expressões de tratamento para intensificar a recategorização" (QUEIROZ, 2015, p. 54).

Algo que julgamos importante observar é que, de um modo geral, as variações que Jayme imprimiu aos seus modos de evocar Maria não geraram expressões tão inovadoras, uma vez que grande parte das diferenças são resultantes apenas da inserção de modificadores, como nos casos de Minha querida noivinha, Minha enternecida amada noivinha. No Quadro 2, temos as cinco expressões mais frequentes nas cartas do personagem, as quais, mesmo diferindo entre si, mantêm a tônica de exaltação à figura de Maria por meio de um tratamento afetuoso. Para nós, a polidez aparece no discurso de Jayme quando identificamos o que Leech (2005) considera como aprovação, ou seja, Jayme procura a aprovação da sua própria face quando aceita a representação de Maria.

${ }^{5}$ Esse levantamento, realizado com o acervo completo das cartas trocadas entre Jayme e Maria, está disponível em Queiroz (2015) e foi disposto em dois gráficos distintos: um contendo somente as formas de tratamento utilizadas por Jayme para referir-se a Maria e o outro com as expressões usadas por Maria para dirigir-se a Jayme. 
Quadro 2 - Formas de tratamento mais frequentes direcionadas a Maria

\begin{tabular}{|c|c|}
\hline Formas de tratamento & Porcentagem \\
\hline minha querida & $22,8 \%$ \\
\hline minha flor & $21,3 \%$ \\
\hline minha querida noivinha & $11,9 \%$ \\
\hline minha santa & $5,4 \%$ \\
\hline Querida Mariquinhas & $3,5 \%$ \\
\hline
\end{tabular}

Fonte: Elaborada pelas autoras.

Um dos aspectos que permitiram a variabilidade de expressões referenciais parece ter sido a facilidade que Jayme demonstrava no trato com a língua escrita. Ao que parece, essa desenvoltura teria relação com o ofício que ele desempenhava. Por meio da leitura de algumas cartas, percebemos que Jayme provavelmente era funcionário de um escritório da cidade do Rio de Janeiro, o que talvez favorecesse o contato com a língua escrita.

(1)

Espero-te minha flor no sábado aonde combinamos, na Rua Buenos Aires esquina com Uruguaiana as $\mathbf{6}$ horas, mas eu vou pedir para sahir as 15 para as 6 horas [...]. (15/02/1937, Jayme-Maria).

(2)

[...] Desejo saber minha flor se de fato tens confiança em mim, sofro ainda mais por isso, tenho andado muito adoentado estes dias. No escritorio querem por força que eu vá a um medico já chegaram a falar com o Senbor. Mario e ele disse para que eu mo trata-se, porque ele me dá as férias se eu quiser, [...]. (24/01/1937, JaymeMaria). 
Em (1), observamos que Jayme quer encontrar Maria no cruzamento entre duas ruas do centro do Rio de Janeiro (na Rua Buenos Aires esquina com Uruguaiana) e, para isso, pretende sair mais cedo do que parece ser seu local de trabalho. Provavelmente, Jayme trabalhava em um escritório cujo chefe era o Senhor Mário, como verificamos em (2): no escritório [...] chegaram a falar com o Senhor Mario e ele disse para que eu mo trata-se, porque ele me dá as ferias se eu quizerer.

Além da desenvoltura que Jayme demonstra ter com a língua escrita, parece-nos que outras explicações para a diversidade de formas que verificamos em sua escrita são a extensão de suas cartas, que, em sua maioria, são longas, e a maior quantidade delas ${ }^{6}$. Possivelmente, Jayme fosse mais competente linguisticamente pelo seu frequente contato com a língua.

Diferentemente do que observamos nas cartas de Jayme, nas de Maria verificamos apenas 71 (setenta e uma) variedades de formas interpelativas. Uma explicação para essa diferença seria a extensão da amostra pesquisada: além de o número de cartas do personagem feminino corresponder a menos da metade do número produzido pelo masculino, há também uma diferença quanto à extensão dos textos. As cartas de Maria, conforme verificamos, são em geral mais sucintas que as de Jayme. Esses dois aspectos justificariam a menor variedade de expressões de tratamento utilizadas por ela para se referir a Jayme.

Observando, porém, as formas interpelativas mais recorrentes no discurso de Maria, dispostas no Quadro 3, percebemos que ela seguia, de certo modo, a mesma estratégia de Jayme para variar as expressões: a inserção de itens modificadores no sintagma. Podemos dizer que a exaltação da figura seria o motivo maior para a escrita e, consequentemente, para a escolha das formas de invocar esse ser.

${ }^{6}$ Das 92 cartas que compõem o acervo Jayme e Maria, 64 cartas são de Jayme e 28 cartas de Maria. 
Quadro 3 - Formas de tratamento mais frequentes direcionadas a Jayme

\begin{tabular}{|c|c|}
\hline Formas de tratamento & Porcentagem \\
\hline Jayme & $15,5 \%$ \\
\hline Meu querido noivinho & $11,3 \%$ \\
\hline Meu noivinho Jayme & $9,9 \%$ \\
\hline Meu queridinho noivinho & $7,0 \%$ \\
\hline Meu filhinho & $5,6 \%$ \\
\hline
\end{tabular}

Fonte: Elaboradas pelas autoras.

Observamos que, no discurso de $\mathrm{Maria}^{7}$, são frequentes as marcas de informalidade e de oralidade, o que sugere sua pouca escolaridade. Silva (2012) destaca que, nas missivas de Maria, há diversos problemas de ortografia e de pontuação, além de certa insegurança no que respeita à grafia das palavras. No recorte (3), por exemplo, Maria utiliza de forma redundante o pronome oblíquo te: 0 retrato que te amostrei-te.

(3)

[...] Tu me pediste o retrato que te amostrei-te no Domingo este retrato eu dei a minha irman ja a muito tempo [...]. (06/10/1936).

Quando voltamos o "olhar para além do campo imediato de co-presença" (HANKS, 2008, p. 189), precisamos considerar que a subjetividade de Maria está atrelada à representação sócio-histórica da mulher

${ }^{7}$ Destacamos que o acesso da mulher à escola era limitado. Conforme Almeida (2008, p. 79), "as famílias e a própria configuração social brasileira das últimas décadas do século XIX e primeiras do século XX marcavam os papéis femininos de forma tal que não era possível fazer a mulher letrada." 
no Brasil oitocentista e novecentista. Para Del Priore (2006), citada em Queiroz (2015, p. 57), no final do século XIX e na primeira metade do século XX, “a mulher mostrava-se submissa diante da estrutura patriarcal e recebia a função de dirigir o lar e de sempre estar disponível para sua família e para seu marido".

Além da "pressão" social influenciando a constituição da subjetividade de Maria, percebemos em suas cartas o uso da polidez, vista sob a ótica de Leech (2005), quando Maria pratica diante de Jayme a autodepreciação. Ela demonstra polidez quando elogia a "fluência" dele com as palavras mesmo que isso promova a sua própria desvalorização, como podemos observar em (4).

(4)

$[\downarrow]$ não repares a minha carta nei os meus eros, eu não sei escrever cartas de amor como voce eu quando lei chego a chorar, voce sabe que eu sou uma burinha. $[\downarrow](07 / 10 / 1937$, Maria-Jayme).

Essa atitude de Maria também se alinha ao que enuncia Goffman (2011). Para o autor, uma pessoa, ao elogiar os outros, é capaz de privar-se ou depreciar-se, o que leva os juízos para "além daquilo que provavelmente seria justo" (p. 36). Essa pessoa, segundo o autor, deixa que os outros lhe atribuam juízos favoráveis e contribui com juízos desfavoráveis sobre si própria.

\section{A (re)construção da história de Jayme e Maria}

Para (re)construir o self e o outro na correspondência trocada entre Jayme e Maria, retomamos a história de amor desses dois sujeitos, organizando-a em três fases distintas ( $O$ prelúdio, $O$ climax e $O$ desenlace). Mesmo que não haja um aspecto formal que explicite essa discretização das fases, destacamos que a leitura do corpus completo (92 cartas) possibilitou que as inferíssimos.

$\mathrm{Na}$ fase $O$ prelúdio, estão os momentos $A$ viagem, a chegada e permanência de Maria e A negociação e a consolidação dos sujeitos. O primeiro diz respeito à viagem de Maria ao Município Paulo de Frontin. Nesse momento, a 
correspondência entre o casal de namorados centra-se na saudade provocada pela distância que os separa. Inferimos esse argumento do seguinte trecho (recorte 5) enunciado por Jayme: "Estimo que a viagem tenha te corrido maravilhosamente bem. Embora tivesses partido hoje só em pensar que tenho de passar uns tempos sem te ver, ja comeco a sentir os tormento da saudade."

(5)

\section{Cara Mariquinhas}

Estimo que a viagem tenha te corrido maravilhosamente bem. Embora tivesses partido hoje só em pensar que tenho de passar uns tempos sem te ver, ja começo a sentir os tormento da saudade, meu anjo eu falo com toda sinceridade eu falei contigo que iriate visitar no $3^{\circ}$ domingo, [...].

Tu bem sabes minha flor o quanto eu te adoro e te amo, mas podes ficar certa, que de domingo para cá senti o meu amor aumentar muito mais. Só a ti é que eu dedico toda a minha vida, e os meus momentos, tú es a deusa que embala-me nos meus sonhos de ilusão,[...]. (09/09/1936, Jayme-Maria).

Ainda nesse trecho da carta saudosa de Jayme, notamos que, mesmo que esse personagem pareça, em um primeiro momento, distanciar-se de Maria quando utiliza o modificador Cara na expressão vocativa Cara Mariquinhas, ele acaba estabelecendo certa proximidade ao conferir um caráter mais íntimo à sua argumentação durante a reconstrução da imagem da namorada por meio de diversas faces (Cara Mariquinhas $\rightarrow$ meu anjo $\rightarrow$ minha flor $\rightarrow$ a deusa que embala-me nos meus sonhos de ilusão). Essa descoberta na missiva do noivo de Maria nos aproxima, portanto, da reflexão de Goffman (2011, p. 17), a qual considera que uma pessoa pode "possibilitar que outra pessoa assuma uma linha ${ }^{8}$ melhor do que seria capaz de assumir sozinha”. Para nós,

${ }^{8}$ A linha, conforme Goffman (2011, p. 13), constitui “um padrão de atos verbais e não-verbais com o qual ela expressa sua opinião sobre a situação, e através disto sua avaliação sobre os participantes, especialmente ela própria. Não importa que a pessoa pretenda assumir uma linha ou não, ela sempre o fará na prática”. 
Jayme autoriza uma "linha melhor" para a noiva quando a "presenteia" com novas faces durante o fluxo do seu discurso lírico.

No recorte (6) a seguir, que traz, ao que parece, a resposta de Maria à carta de Jayme, esperávamos que as formas de referir convocadas por Maria progredissem para um tratamento cada vez mais amoroso, como ocorreu na carta de Jayme; no entanto, ela utiliza somente a categoria Jayme. Possivelmente, como Maria estava na casa da irmã em Paulo de Frontin, isto é, estava em um novo "cenário" (aqui fais muito fro e bom para que e casado aqui sotem mato tem muito sapo grilo e gafanhoto sam os bichos do lugar), ela sentia necessidade de relatar os acontecimentos desse novo cotidiano.

(6)

Querido Jayme

Saudades

Desejo que ja estejas passando melhor de saude que e o meu deseijo eu e a Hilda chegamos bem grasas a Deus mais com muita chuva aqui fais muito fro e bom para que e casado aqui so tem mato tem muito sapo grilo e gafanhoto sam os bichos do lugar. Jayme isto não entereça o que entereca e o nosso a mor eu tenho chorado muito con saldades tuas aqui e muito triste era bom se voce estivese aqui com migo. Jayme manda-me dizer se atua mãe falou alguma cousa com voce au meu respeito [...]. (10/09/1936, Maria-Jayme).

Quando o discurso de Maria se volta para as novidades da viagem, lembramo-nos do que afirma Biber (1988) sobre os textos escritos. Consoante o autor, as relações entre os interlocutores são mantidas em função da aceitação do outro. No momento em que o leitor aceita essas relações, o escritor tende a não modificar sua postura, a fim de manter a ligação com o seu destinatário. Para nós, Maria parece priorizar o discurso mais informativo como forma de preservar o elo com o namorado e de preencher a ausência do discurso lírico, que era comum nas missivas dele e que ela, apesar de julgar ser a melhor forma de escritura, não conseguia produzir.

Além desse posicionamento informativo de Maria, observamos, ainda no recorte (6), sua necessidade de namorada de Jayme de saber notícias 
sobre a "sogra" (Jayme manda-me dizer se atua mãe falou alguma cousa com voce au meu respeito). Esse interesse de Maria pela mãe de Jayme é persistente em algumas cartas da primeira fase, o que nos levou a "desconfiar" da causa para esse estado de espírito demonstrado pela personagem.

A comprovação de tais suspeitas só pode ser confirmada durante a leitura das missivas que compõem o que consideramos a segunda fase da história de Jayme e Maria ( $O$ clímax). Essa fase é constituída pelo momento A perseguição ao relacionamento de Jayme e Maria. Indícios dessa perseguição ficam mais evidentes quando nos voltamos para o que menciona Maria no trecho a seguir (recorte 7). Nele, ela narra a conversa que ocorreu entre seu irmão Neuzinho e o irmão de Jayme.

(7)

[...] O meu irmão Neuzinho esteve com o teu irmão ontem elle esteve jogando o verde no Neuzinho mais elle não caiu, voce pergunta au Neuzinho o que elles falarão, o teu irmão perguntou a onde a gente morava o Neuzinho diçe que morava em catumbi [...]. (12/02/1937, Maria-Jayme).

Esse recorte nos permite observar que o casal partilhava um alto grau de "conhecimento mútuo" (PINKER, 2008, p. 473) que nós, leitores, não dominamos. O trecho "elle esteve jogando verde no Neuzinho mais elle não caiu”, por exemplo, que alude ao ditado popular "jogando verde para colher maduro", parece indicar a existência de algo compartilhado pelo casal e desconhecido pela família de Jayme. Inferimos, então, que essa passagem da carta de Maria seria uma pista de que o relacionamento entre os namorados não era aprovado pela família de Jayme, o que os motivava a guardá-lo em segredo.

Contamos, até aqui, um pouco da história de nossos protagonistas, a fim de termos subsídios suficientes para construirmos o que parece ser a causa que dificulta o relacionamento entre Maria e Jayme: Hilda. Apesar de estar presente constantemente nas cartas dos namorados, é somente em uma das missivas de Jayme (recorte 8) que o papel de Hilda na história do casal é posto em evidência. 
(8)

[...] Eu quero que tú não prohibas a Hilda de brincar, porque nos que somos marmanjos gostamos de brincadeiras. porque ela não é só tua, e nossa, pertence-me tambem, não amo só a mãe dela, mas ela tambem, porque ela é teu fruto, então se és minha ela tambem é minha.

Recomendações aos teus beijos para a Hilda "minha futura filha", [...]. (5/10/1936, Jayme-Maria).

A leitura desse trecho nos esclarece, portanto, que Hilda é filha de Maria (ela não é só tua, e nossa, pertence-me tambem, não amo só a mãe dela, mas ela tambem, porque ela é teu fruto). Inferimos, assim, que Maria é mãe solteira, visto que o pai de Hilda não é mencionado em nenhuma das 92 cartas. $O$ fato de Maria ser mãe solteira possivelmente desagradava os pais de Jayme, já que ela "tinha uma filha, fruto de um relacionamento com outra pessoa e, para os padrões da época, isso não era bem visto” (SILVA, 2012, p. 48). Isso nos remete ao que afirma Del Priore (2006), que a família e os amigos influenciavam a escolha dos pretendentes, visto que casamentos contra a vontade da família eram desacreditados. Além disso, precisamos mencionar que inferir todas essas ideias do discurso de Jayme só é possível porque estamos considerando a colocação de Hanks (2008, p. 184) sobre a incorporação: "no curso da vida social, não há situação que não esteja intimamente ligada a um cenário e não há cenário separado de semiose".

Essa perseguição imposta a Maria parece atenuar-se na terceira fase (O desenlace) da história de nossos protagonistas. Essa fase, composta pelo momento $A$ calmaria representada pela subjetividade lírica de Jayme, apresenta mais cartas de Jayme do que de Maria. Em vista disso, evidenciamos, inevitavelmente, o discurso dele nesse momento.

(9)

Minha enesquecivel noivinha, saudades incontadas

$[\cdots]$

Eu sinto que nesta vida já tenho tudo preparado, tenho a carreira mais ou menos bem graças a Deus, e tenho a flor de meus sonhos a deusa que mais amo e mais idolatro, a santa que inspira-me e 
me da forças que é voce, só falta-me a felicidade que a terei dentro em breve, que é possuindo-te como minha esposa e como minha eterna companheira, só assim sentiria-me feliz.

[...] o meu coração terás eternamente em teu peito batendo dando-te vida, e o teu viverá em meu peito dando-me vida e alento para continuar dedicando a ti todo o amor que mereces, porque a flor que enalteceme, que me ensina a amar e me ensina o caminho da felicidade és tú, [...]. (13/02/1937, Jayme-Maria).

Em (9), Jayme reconstrói, em uma longa cadeia de transformações, a figura de Maria não só por meio de sintagmas nominais, mas também por "unidades de ordem maior" (CUSTÓDIO FILHO, 2011, p. 174): Minha enesquecivel noivinha $\rightarrow$ a flor de meus sonhos $\rightarrow$ a deusa que mais amo e mais idolatro $\rightarrow$ a santa que inpira-me e me da forças $\rightarrow$ minha esposa e [...] minha eterna companheira $\rightarrow$ a flor que enalteceme, que me ensina a amar e me ensina o caminho da felicidade. Essa ampla rede de reconstruções que, sob a ótica da Teoria da Acessibilidade (ARIEL, 2001), poderia representar um referente pouco acessível e, em razão disso, construído por expressões mais informativas, seria, na verdade, o modo pelo qual Jayme demonstra todo seu sentimento. Como já mencionamos em Queiroz (2015, p. 90), “O dizer e o redizer parece constituir uma tentativa de afastar qualquer dúvida quanto à verdade que é expressa: o sentimento de paixão do escrevente pela sua interlocutora".

Afora o enaltecimento do sentimento de Jayme, uma das regras pragmáticas, o elogio, admitida por Leech (2005), manifesta-se nessa passagem do texto do noivo de Maria. O uso de formas elogiosas serviria para enaltecer a imagem de Maria, evidenciando as suas qualidades (a flor de meus sonhos a deusa que mais amo e mais idolatro, a santa que inspira-me e me da forças). Consideramos também que, ao elogiar a noiva, Jayme "adoça" (PINKER, 2008, p. 433) seu discurso para demonstrar toda sua devoção à namorada: $a$ flor que enalteceme, que me ensina a amar e me ensina o caminho da felicidade és tú.

Embora Jayme e Maria tenham enfrentado muitas dificuldades, inferimos, como já citamos em Queiroz (2015, p. 95), que o final desta história de amor foi feliz, "baseados no seguinte trecho da carta de Jayme do dia 16 de março de 1937: só falta-me a felicidade que a terei dentro em breve, que épossuindo-te como minha esposa e como minha eterna companheira". 


\section{Considerações Finais}

Neste trabalho, fomos norteados pelo propósito de promover o resgate da história de Jayme e Maria buscando informações na interação via cartas trocadas pelo casal. Para tanto, recorremos à interface entre os fundamentos da Linguística Textual, com ênfase na Referenciação, e da Pragmática, com foco em alguns aspectos da Teoria da Polidez. Essa interação entre as duas perspectivas teóricas nos possibilitou algumas "descobertas", na medida em que nos permitiu empreender uma incursão atenta nos diálogos travados entre os personagens.

Nesses diálogos, destacamos a diversidade de expressões para se referir ao outro utilizadas por Jayme e Maria. Observamos que ele tentava usar expressões inovadoras para dirigir-se a Maria, enquanto ela, provavelmente, devido às imposições da sociedade patriarcal e à pouca habilidade com as estruturas da língua, priorizava o uso de expressões mais recatadas para referir-se a Jayme. Destacamos também que Maria utilizava, com frequência, elogios para enaltecer a fluência de Jayme com a língua, gerando com isso a autodepreciação. Verificamos, também, que Jaime respondia a essa atitude de Maria praticando, em diversas de suas cartas, o ato polido de preservar a imagem da noiva.

Assim, observamos que os estudos sobre Linguística Textual nos permitiram verificar o funcionamento prático do referente que se recategoriza intra e intertextualmente e a forma como nosso sistema inferencial expande esses referentes para além do enunciado, fazendo emergir as partes submersas do grande "iceberg" que se esconde na materialidade linguística. Por outro lado, percebemos que os princípios da Teoria da Polidez contribuíram sobremaneira para explicitar boa parte do que estava implícito. Entendemos, na prática, a observação de Pinker (2008) de que a cortesia e até mesmo as ambiguidades dos enunciados são correntes no uso da língua e cooperam para a aprovação dos nossos discursos.

Concluindo, ressaltamos a pertinência do diálogo entre os campos de estudo da Referenciação e da Polidez como um caminho para a compreensão de textos. 


\section{Referências}

ALMEIDA, N. M. A. Jornal das moças: leitura, civilidade e educação femininas (1932-1945). 2008. Tese (Doutorado em Educação Brasileira) Universidade Federal do Ceará, Fortaleza. Disponível em: <http://bit.ly/2jGO0mV>. Acesso em: 29 jan. 2015.

ARIEL, M. Acessibility theory: an overview. In: SANDERS, T.; SCHILPEROORD, J.; SPOOREN, W. Text representation: linguistics and psycholinguistics aspects. Amsterdam; Philladelphia: Benjamins, 2001. p. 29-89.

BAKHTIN, M. O enunciado, unidade da comunicação verbal. In: BAKHTIN, M. Estética da criação verbal. 3. ed. Tradução Maria Ermantina Galvão. São Paulo: Martins Fontes, 1997.

BAKHTIN, M. Marxismo e filosofia da linguagem. 12. ed. São Paulo: Hucitec, 1996.

BIBER, D. Variation across speech and writing. Cambridge: Cambridge University Press, 1988.

BROWN, P.; LEVINSON, S. C. Politeness: some universals in language usage. Cambridge: Cambridge University Press, 1987 [1978].

CAVALCANTE, M. M. Os sentidos do texto. São Paulo: Contexto, 2013. CIULLA, A. Os processos de referência e suas funções discursivas: o universo literário dos contos. 2008. Tese (Doutorado em Linguística) Universidade Federal do Ceará, Fortaleza.

CUSTÓDIO FILHO, V. Múltiplos fatores, distintas interações: esmiuçando o caráter heterogêneo da referenciação. 2011. Tese (Doutorado em Linguística) -Universidade Federal do Ceará, Fortaleza.

DEL PRIORE, M. História do amor no Brasil. São Paulo: Contexto, 2006. Disponível em: <http://bit.ly/2iGug6u>. Acesso em: 19 mar. 2012. 
FARACO, C. A. Linguagem \& diálogo: as ideias linguísticas do círculo de Bakhtin. São Paulo: Parábola, 2009.

GOFFMAN, E. A representação do eu na vida cotidiana. Tradução Maria Célia Santos Raposo. Petrópolis: Vozes, 1975.

GOFFMAN, E. Ritual de interação: ensaios sobre o comportamento face a face. Tradução Fábio Rodrigues Ribeiro da Silva. Rio de Janeiro: Vozes, 2011.

HANKS, W. F. O que é contexto? In: BENTES, A. C.; REZENDE, R. C.; MACHADO, M. A. R. (Org.). Lingua como prática social: das relações entre língua, cultura e sociedade a partir de Bourdieu e Bakhtin. São Paulo: Cortez, 2008.

LEECH, G. Principles of Pragmatics. London: Longman, 1983.

LEECH, G. Politeness: is there an Eastwest divide? Journal of Foreign Languages, n. 6, n. 160, Nov. 2005. Disponível em: <http://bit.ly/2zZs0yJ>. Acesso em: 20 out. 2014.

MARCUSCHI, L. A. Do código para a cognição: processo referencial como atividade criativa. In: MARCUSCHI, L. A. Cognição, linguagem e práticas interacionais. Rio de Janeiro: Lucerna, 2007. p. 82-103.

MEAD, G. H. Espiritu, persona e sociedad. Barcelona: Paidós, 1973.

MONDADA, L.; DUBOIS D. Construção dos objetos de discurso e categorização: uma abordagem dos processos de referenciação. In: CAVALCANTE, M. M.; RODRIGUES, B. B.; CIULLA, A. (Org.) Referenciação. São Paulo: Contexto, 2003. p. 17-52.

PINKER, S. Os jogos que as pessoas fazem. In: PINKER, S. Do que é feito o pensamento: a língua como janela para a natureza humana. Tradução Fernanda Ravagnani. São Paulo: Companhia das Letras, 2008. p. 425-480.

QUEIROZ, A. A. Referenciação e polidez em cartas de amor: o resgate da história de Jayme e Maria por meio do self e do outro. 2015. Dissertação (Mestrado em Linguística Aplicada) - Universidade Estadual do Ceará, Fortaleza. 
SACRAMENTO, S. O amor em terras brasileiras. Estudos Feministas, Florianópolis, v. 14, n. 1, p. 305-323, jan./abr. 2006. Disponível em: <http://bit.ly/2BE35O9>. Acesso em: 05 jun. 2012.

SALOMÃO, M. M. M. A questão da construção do sentido e a revisão da agenda dos estudos da linguagem. Veredas: Revista de Estudos Lingüísticos, Juiz de Fora, v. 3, n. 1, p. 61-79, 1999. Disponível em: <http://bit.ly/2zIYCbA>. Acesso em: 07 jul. 2014.

SANTOS, E. A. A emergência da (inter)subjetividade em interação virtual: um estudo sobre negociação de sentidos e construção de referentes no fórum da comunidade ${ }^{-}$Professores do Ceará. 2013. Dissertação (Mestrado em Linguística Aplicada) - Universidade Estadual do Ceará, Fortaleza.

SILVA, E. N. Cartas amorosas de 1930: o tratamento e o perfil sociolinguístico de um casal não ilustre. 2012. Dissertação (Mestrado em Letras Vernáculas - Língua Portuguesa) - Universidade Federal do Rio de Janeiro, Rio de Janeiro.

SILVA, F. O.; CUSTÓDIO FILHO, V. O caráter não linear da recategorização referencial. In: CAVALCANTE, M. M.; LIMA, S. M. C. de (Org.) Referenciação: teoria e prática. São Paulo: Cortez, 2013.

SOBRAL, A. Ato/atividade e evento. In: BRAIT, B. (Org.). Bakhtin: conceitos-chave. São Paulo: Contexto, 2013. p. 11-36.

UNIVERSIDADE FEDERAL DO RIO DE JANEIRO. Laboratório de História do Português Brasileiro. Disponível em: <http://bit.ly/2npnDaj>. Acesso em: 17 set. 2011.

WITTGENSTEIN, L. Investigações filosóficas. 2. ed. Tradução Marcos G. Montagnoli. Petrópolis: Vozes, 1996.

Recebido em: 25/06/2016 Aceito em: 05/10/2016 